\title{
FFP3, FFP2, N95, surgical masks and respirators: what should we be wearing for ophthalmic surgery in the COVID-19 pandemic?
}

\author{
Kenneth K. W. Li ${ }^{1,2} \cdot$ Antonia M. Joussen ${ }^{3}$ • Joseph K. C. Kwan ${ }^{4}$ - David H. W. Steel ${ }^{5,6}$ (I)
}

Received: 8 May 2020 / Revised: 8 May 2020 / Accepted: 12 May 2020 / Published online: 26 May 2020

(C) Springer-Verlag GmbH Germany, part of Springer Nature 2020

This is a fearful time and wearing appropriate personal protective equipment (PPE) has become a topic we all need to be experts in. It has become particularly relevant with the worldwide shortages that have become daily headlines.

Elective surgery has been delayed until the current crisis has settled and in most affected countries ophthalmic surgeons are now performing only emergency or urgent surgery. Vitreoretinal surgery in particular, however, still carries on due to the numerous conditions we treat which are time critical. Recently, it has been recommended by the Royal College of Ophthalmologists (RCOphth) and the British and Eire Association of Vitreoretinal Surgeons (BEAVRS) that we use filtering face-piece (FFP) 3 masks during vitrectomy surgery in all patients, in addition to eye protection related to the potential for aerosol production [1]. This has been backed by the American Society of Retinal Specialists (ASRS) [2]. Whilst much is still unknown regarding transmission of the SARS-CoV-2 coronavirus, it is interesting to review some of the factors behind this recommendation.

This article is part of the topical collection Perspectives on COVID-19.

Joseph K. C. Kwan

joekwan@ust.hk

David H. W. Steel

david.steel@newcastle.ac.uk

1 Department of Ophthalmology, United Christian Hospital, Hospital Authority, Kwun Tong, Hong Kong SAR

2 Department of Ophthalmology, Tseung Kwan O Hospital, Hospital Authority, Tseung Kwan O, Hong Kong SAR

3 Department of Ophthalmology, Charité University Medicine Berlin, Berlin, Germany

4 Division of Environmental and Sustainability, Hong Kong University of Science and Technology, Clear Water Bay, Hong Kong SAR

5 Sunderland Eye Infirmary, Sunderland, UK

6 Bioscience Institute, Newcastle University, Newcastle, UK
Standard disposable surgical face masks have been the rule in most of our theatres for years [3]. Their function has thought to be two-way but primarily to prevent the passage of germs from the surgeon's nose and mouth into the patient's wound. The evidence in terms of reducing infection rates is surprisingly unclear; however, with COVID-19, we are perhaps more concerned with transmission to the surgeon [4].

Current data suggest person-to-person transmission most commonly happens during close exposure to a person infected with SARS-CoV-2. It is important to remember that recent studies have shown that people with COVID-19 frequently do not report typical symptoms such as fever or respiratory symptoms, and go through a pre-symptomatic phase of several days when they are infectious. Infection is thought to occur primarily via respiratory droplets produced when the infected person speaks, coughs, or sneezes. Droplets can land in the mouths, noses, or eyes of people who are nearby or possibly be inhaled into the lungs of those within close proximity. It is thought that airborne transmission over long distances is unlikely, but the contribution of small particles in aerosols is currently uncertain.

An aerosol (abbreviation of "aero-solution") in the context of COVID-19 is a suspension of fine liquid droplets in air. Although well known to occur with coughing and sneezing, they can also be produced during talking and normal breathing [5].

Respiratory produced aerosol droplets are believed to be generated primarily in the lungs during inhalation, via a "fluid film burst" mechanism in which aerosol particles are produced as a result of the clearance of fluid closures formed in the bronchioles following exhalation [6]. Similarly, laryngeal droplet generation is also believed to occur during speaking because of fluid films bursting when the vocal folds adduct and vibrate within the larynx or during coughing and sneezing due to shear stress in the mucus-air interface within the trachea [7].

The sizes of cough-generated particles affect their behaviour. Current infection control guidelines distinguish between 
"droplet precautions," which are needed for diseases thought to spread primarily by larger spray droplets, and "airborne precautions," needed for diseases that spread via small aerosols [8].

Large droplets (greater than $\sim 50 \mu \mathrm{m}$ ) are primarily affected by gravity; they follow a ballistic trajectory and impact on surfaces or fall onto surfaces within a meter of the source. Intermediate-sized droplets $(\sim 10-50 \mu \mathrm{m})$ can deposit by impaction but can also be carried further from the source by the cough air flow and can travel $2 \mathrm{~m}$ or more before settling. Small droplets forming an aerosol (less than $\sim 10 \mu \mathrm{m}$ ) are much less prone to impaction and can remain airborne for an extended time and spread by air currents [9]. Indeed, prolonged environmental contamination by SARS-CoV-2 is a cause for concern, and in a recent laboratory study, viable SAR-CoV-2 was detected in aerosols up to $3 \mathrm{~h}$ postaerosolization [10].

A waterproof surgical mask can protect the wearer from the risk of splashes of biological fluids and can indeed filter out viruses, but is not designed to provide an airtight seal around the mouth and nose.

A filtering respirator mask is personal protective equipment that is designed to prevent the wearer from inhaling aerosols that are health hazards. On average, the protection factors of FFP respirators are 12 to 16 times greater than those of surgical masks, although the fit to the wearers face is the most important factor in their effectivity, and systematic 'fit' testing is vital [11]. In Europe, respirators must meet the European standard EN 149:2001 which has 3 classes of disposable particulate respirators [12]. FFP1 refers to the least filtering of the three masks with an aerosol filtration of at least $80 \%$ for $0.3 \mu \mathrm{m}$ particles, and is mainly used as an environmental dust mask. FFP2 masks have a minimum of $94 \%$ filtration percentage whilst FFP3 masks are the most filtering mask of the FFPs. With a minimum filtration percentage of $99 \%$, they protect against very fine particles such as asbestos.

In the USA, respirators must meet NIOSH (National Institute for Occupational Safety and Health) standards [13]. Within this standard, there are several classes of respirators, $\mathrm{N}$, $\mathrm{R}$, and $\mathrm{P}$, depending on the degree of oil resistance, not relevant to COVID-19. The number after the letter indicates the percentage of filtration of suspended particles. N95 and FFP2 are approximately equivalent and are the minimum advised for working with aerosol producing procedures with COVID19 positive patients. Whilst the virus itself measures $0.06 \mu \mathrm{m}$, it will usually be associated with water increasing its size in the acute aerosol production stages.

Some surgical procedures are known to produce aerosols $[14,15]$. These include bronchoscopy, cardiopulmonary resuscitation, intubation, and extubation but also include those using high speed devices most typically drills in orthopaedics and dentistry. The question arises as to whether vitrectomy, with blade rates up to 10,000 cycles per minute, are aerosol producing. There is no definition that we could find of high speed but it is typically used when referring to drills operating at over 50,000 CPM. Phacoemulsification or lens fragmentation is often combined with vitrectomy, where ultrasonic induced probe movement at $>50,000 \mathrm{~Hz}$ occurs. Again, this is typically carried out within fluid however and it is not known if either vitrectomy or ultrasonic lens disruption is associated with significant aerosol creation. Vapour is certainly visible to the naked eye when probes are tested in shallow saline outside the eye. Indeed, aerosols are only produced when an air current moves across the surface of a film of liquid. In vitrectomy, the cutter blade moves within the fluid filled vitreous cavity in an effectively closed system. Cutting is sometimes done at air/ fluid interfaces; however, all fluid and air is aspirated to the machine cassette and collected in a reservoir in a closed system. If aerosol does generate in the vitreous cavity, the majority will be carried to the cassette of the vitrectomy machine. Certain make of vitrectomy machines, for example Constellation $\AA$, has integrated filters in the cassette, with aerosol filtration efficiencies of $0.2 \mu \mathrm{m}$, and should filter off any aerosol before it is vented into the environment (personal communication: Alcon Inc).

Another question is whether SARS-CoV-2 is present in vitreous. Relevant to ophthalmologists, several published reports suggest that SARS-CoV-2 can cause conjunctivitis. This appears to be uncommon $(\sim 1-5 \%)$ and not always associated with the presence of virus in the tear film, but certainly it is present in tears in some people with active COVID-19 [16, 17]. The human eye has its own intraocular renin-angiotensin system (RAS), a system that has been the interest of many projects focusing on developing anti-glaucomatous drugs. Angiotensin converting enzyme 2 (ACE2), a membrane bound protein that is the entry receptor of SARS-CoV-2, is certainly present in the retina and has been detected in aqueous [18]. Two animal coronaviruses infections (murine and feline $\mathrm{CoV}$ ) have been reported to cause retinal involvement with a vasculitis but this has not been reported with SARS-CoV-2, nor its presence in human vitreous to date.

All things considered unless the viral carriage on the ocular surface is extremely high, the amount of aerosol released into the environment of the operating theatre should be minimal.

Aside from masks, ophthalmic theatres are typically ventilated with positive pressure systems, exchanging the air $\sim 20$ times an hour, with inflowing air passing through a highefficiency particulate air (HEPA) filters where particles down to nanosize are removed. It is recommended that ventilation should remain fully on during surgical procedures where patients may have COVID-19 infection. The rapid dilution of these aerosols by operating theatre ventilation will also protect operating room staff. Air passing from operating theatres to adjacent areas will be highly diluted and is not considered to be a risk. The use of negative pressure theatre, if available, can of course eliminate this risk. 
So, in conclusion, are we at more risk during vitrectomy surgery? It seems unlikely but possible based on the above discussion and it is perhaps 'better to be safe than sorry' if PPE equipment of FFP3 and N95 mask supply makes this feasible. Finally, the RCOphth and BEAVRS have also made a number of other practical common sense suggestions that we should all heed: perform surgery under LA whenever possible (to reduce GA aerosol production), use additional drapes if needed to reduce flow from the naso-pharynx, only experienced surgeons should operate to minimise the length of the operation, and non-essential staff should not enter the operating theatre during the operation.

\section{Compliance with ethical standards}

Conflict of interest Professor David Steel reports grants and personal fees from Alcon, personal fees from Roche, personal fees from Gyroscope, and grants from Bayer, outside the submitted work.

Professor Antonia Joussen reports grants from Bayer and Novartis, outside the submitted work, and is a consultant for Allergan, Bayer, Novartis, and Roche.

Professor Joseph Kwan and Dr. Kenneth Li report no conflicting relationship.

\section{References}

1. The Royal College of Ophthalmologists. Vitreoretinal surgery during the COVID-19 pandemic. 2020;(April):30420. https://www. rcophth.ac.uk/wp-content/uploads/2020/04/Vitreoretinal-surgerymanagement-guidance-070420.pdf

2. Recommendations for Conducting Vitreoretinal Surgery During the COVID-19 Pandemic Committee for Best Practices for Retinal Surgery during the COVID-19 Pandemic, American Society of Retina Specialists

3. Vincent M, Edwards P (2016) Disposable surgical face masks for preventing surgical wound infection in clean surgery. Cochrane Database Syst Rev 2016(4). https://doi.org/10.1002/14651858. CD002929.pub3

4. Tang GCH, Steel DHW, Li KKW (2020) Why ophthalmologists should mask: a perspective from Hong Kong. Eye. https://doi.org/ 10.1038/s41433-020-0916-y

5. Yan J, Grantham M, Pantelic J et al (2018) Infectious virus in exhaled breath of symptomatic seasonal influenza cases from a college community. Proc Natl Acad Sci U S A 115(5):10811086. https://doi.org/10.1073/pnas. 1716561115
6. Johnson GR, Morawska L (2009) The mechanism of breath aerosol formation. J Aerosol Med Pulm Drug Deliv 22(3):229-237. https:// doi.org/10.1089/jamp.2008.0720

7. Wei J, Li Y (2016) Airborne spread of infectious agents in the indoor environment. Am J Infect Control 44(9):S102-S108. https://doi.org/10.1016/j.ajic.2016.06.003

8. Siegel JD, Rhinehart E, Jackson M, Chiarello L (2007, 2007) Guideline for isolation precautions: preventing transmission of infectious agents in health care settings. Am J Infect Control 35(10 SUPPL. 2). https://doi.org/10.1016/j.ajic.2007.10.007

9. CDC Online Newsroom - Press Release - Interim Guidance Issued for the Use of Facemasks and Respirators in Public Settings During an Influenza Pandemic. https://www.cdc.gov/media/pressrel/2007/ r070503.htm. Accessed April 30, 2020

10. van Doremalen N, Bushmaker T, Morris DH et al (2020) Aerosol and surface stability of SARS-CoV-2 as compared with SARSCoV-1. N Engl J Med 382(16):1564-1567. https://doi.org/10. 1056/NEJMc2004973

11. Lee S-A, Hwang D-C, Li H-Y, Tsai C-F, Chen C-W, Chen J-K (2016) Particle size-selective assessment of protection of European standard FFP respirators and surgical masks against particles-tested with human subjects. J Healthc Eng 2016. https://doi.org/10.1155/ 2016/8572493

12. CEN - Technical Bodies -. https://standards.cen.eu/dyn/www/f?p= 204:110:0::::FSP PROJECT,FSP ORG_ID:32928,6062\&cs= 1FC98AD34A5EE26A0CB5A6155ED4D6E5E. Accessed April 30,2020

13. CDC - The National Institute for Occupational Safety and Health (NIOSH). https://www.cdc.gov/niosh/index.htm. Accessed April 30, 2020

14. Tran K, Cimon K, Severn M, Pessoa-Silva CL, Conly J (2012) Aerosol generating procedures and risk of transmission of acute respiratory infections to healthcare workers: a systematic review. PLoS One 7(4). https://doi.org/10.1371/journal.pone.0035797

15. Boswell C, Longstaff J (2019) Aerosol Generating Procedures (AGPs) Title: Aerosol Generating Procedures (AGPs)

16. Sun X, Zhang X, Chen X et al (2020) The infection evidence of SARS-COV-2 in ocular surface: a single-center cross-sectional study. medRxiv (8197033356) 2020.02.26.20027938. https://doi. org/10.1101/2020.02.26.20027938

17. Zhou Y, Zeng Y, Tong Y, Chen C (2020) Ophthalmologic evidence against the interpersonal transmission of 2019 novel coronavirus through conjunctiva. medRxiv 2020(02):11.20021956. https://doi. org/10.1101/2020.02.11.20021956

18. Seah I, Agrawal R (2020) Can the coronavirus disease 2019 (COVID-19) affect the eyes? A review of coronaviruses and ocular implications in humans and animals. Ocul Immunol Inflamm. https://doi.org/10.1080/09273948.2020.1738501

Publisher's note Springer Nature remains neutral with regard to jurisdictional claims in published maps and institutional affiliations. 